\title{
Observations de la Comète 1890 IV (Zona)
}

faites au Grand Equatorial de l'Observatoire de Bordeaux.

\begin{tabular}{|c|c|c|c|c|c|c|c|c|c|c|c|}
\hline 1890 & T. m. Bord. & $\triangle \mathrm{AR}$ & $\triangle \mathrm{DP}$. & $\mathrm{Cp}$ & Obs. & AR. app. & $|\log p . \Delta|$ & DP. app. & $\log p .4$ & Red. ad l. app. & $*$ \\
\hline éc. $\begin{array}{r}8 \\
28\end{array}$ & $\left|\begin{array}{ccc}7^{\mathrm{h}} & 16^{\mathrm{m}} & 4^{39} 6 \\
6 & 14 & 59.6\end{array}\right|$ & $\begin{array}{l}+1^{12} 10^{5} .96 \\
-131.97\end{array}$ & $\begin{array}{l}-r^{\prime} 32^{\prime \prime} 7 \\
-433.9\end{array}$ & $\begin{array}{c}10 \\
4\end{array}$ & $\begin{array}{l}\text { LP } \\
\text { GR }\end{array}$ & 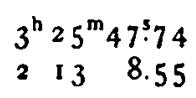 & & $\begin{array}{lll}55^{\circ} & 39^{\prime} & 56.9 \\
59 & 44 & 53.6\end{array}$ & $0.404 n$ & $\begin{array}{l}+3.67-15.8 \\
+3.00-20.7\end{array}$ & I \\
\hline
\end{tabular}

Observateurs: LP $=$ M. L. Picart, GR $=$ M. G. Rayet.

Positions moyennes des étoiles de comparaison pour 1890.0.

\begin{tabular}{|c|c|c|c|}
\hline * & AR. 1890.0 & DP. 1890.0 & Autorité \\
\hline 2 & $\begin{array}{lll}3^{h} & 24^{\text {in }} 33^{5} 11 \\
2 & 14 & 37.5^{2}\end{array}$ & $\begin{array}{l}55^{\circ} 4 I^{\prime} 45^{\prime \prime} 4 \\
5949 \quad 48.2\end{array}$ & $\begin{array}{l}W_{2} 3^{h} \cdot 457 \\
1 / 2\left(W_{2} 2^{h} \cdot 291-92+\text { Par. 2905) }\right.\end{array}$ \\
\hline
\end{tabular}

La comète très faible disparaît avant le lever de la Lune.

1890 Déc. 29.

G. Rayet.

\section{Beobachtungen von Cometen}

angestellt am 12 inch. Aequatoreal der Privatsternwarte in Dresden von Dr. B. von Engelhardt.

\begin{tabular}{|c|c|c|c|c|c|c|c|c|c|c|c|}
\hline 1890 & M. Z. Dresd. & $\Delta \alpha$ & & $\Delta \delta$ & Vgl. & $\alpha$ app. & $\log p . \Delta \mid$ & $\delta$ app. & $\log p . \Delta$ & Red. ad l. app. & - \\
\hline \multicolumn{12}{|c|}{ Comet 1890 IV (Zona). } \\
\hline Dec. 15 & $\left|7^{h} 48^{m} 32^{s}\right|$ & $+2^{m} 6.10$ & + & $2^{\prime} 37 \cdot 4$ & 18.6 & $2^{h} 54^{m} 27^{s}: 50$ & $9.222 \mathrm{n}$ & $+33^{\circ} I^{\prime} 24^{\prime \prime} .5$ & 0.466 & $+3.44+18: 6$ & I \\
\hline 17 & $783^{2}$ & - I 28.27 & + & 247.6 & 3.1 & $246 \quad 48.45$ & $9 \cdot 320_{n}$ & $+323^{6} 19.3$ & 0.494 & $+3.39+18.9$ & 2 \\
\hline 29 & $6 \quad 3335$ & +229.52 & - & ○ 22.8 & 18.6 & $210 \quad 47.39$ & $9.078_{n}$ & +3039.8 & $0.5 \mathrm{II}$ & $+2.94+21.0$ & 3 \\
\hline
\end{tabular}

Fadenmikrometer. - Dec. I5 $_{5}$. Dichter Nebel. Comet sehr schwach. Falls er keinen sternartigen Kern besitzt, so hat ein in der Cometennebulosität stehendes Sternchen die Einstellungen beeinflusst. - Dec. 1 7 . Nebel und Mondschein. Comet äusserst schwach. Beobachtung unsicher. Die Beobachtung wurde durch gänzliche Bewölkung unterbrochen. - Dec. 29. Luft nebelig. Comet sehr schwach.

$$
\text { Comet } 1890 \ldots \text { (Spitaler Nov. 16). }
$$

Dec. $7|91120|$ to $36.88|-718.3| 17.8|51240.85| 9.5130|+375416.5| 0.467|+4.13+5.8| 4$

Fadenmikrometer. - Luft schlecht, verwaschene Bilder. Der Comet steht zwischen kleinen Sternchen, ist kaum sichtbar und verschwindet oft gänzlich. Beobachtung unsicher, besonders in Decl.

Mittlere Oerter der Vergleichsterne für 1890.0.

\begin{tabular}{|c|c|c|c|c|c|c|c|}
\hline * & $\alpha 1890.0$ & $\delta{ }_{1} 890.0$ & Autorität & * & $\alpha 1890.0$ & $\delta 1890.0$ & Autorität \\
\hline$I$ & 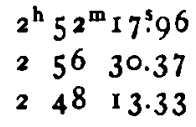 & 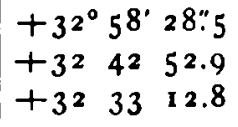 & $\begin{array}{l}\text { Anschluss }(1890.99) \text { an } \\
\text { AG. Leiden } *)\left(W_{2}\right) \\
\text { BB.VI }+322^{\circ} 58\end{array}$ & $\begin{array}{l}3 \\
4\end{array}$ & 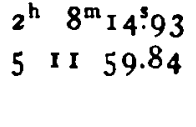 & $\begin{array}{l}+30^{\circ} \\
+38 \text { I } 1 . " 7 \\
+38\end{array}$ & $\begin{array}{l}\text { BB.VI +29.375 } \\
\text { Lal. } 9860\end{array}$ \\
\hline
\end{tabular}

*) Mitgetheilt von Herrn Professor H. G. van de Sande Bakhuyzen.

Dresden 189 I Jan. 3.

B. von Engelhardt. 